\title{
Mathematical Literacy: Myths, further inclusions and exclusions
}

\author{
Cyril Julie \\ School of Science and Mathematics Education, University of the Western Cape \\ cjulie@uwc.ac.za
}

Mathematical Literacy as a new subject in the final three years (grades 10 to 12) of schooling in South Africa is discussed. The discussion is driven by debates and deliberations around the introduction of Mathematical Literacy as they emerged in the public domain and constructs emanating from a diverse field of literature related to both mathematics and mathematical literacy. In particular the National Curriculum Statement Grades 10 to 12: Mathematical Literacy is held in focus and somewhat mirrored against Critical Mathematical Literacy. It is concluded that there should be guarding against Mathematical Literacy degenerating into a $21^{\text {st }}$ century form of arithmetic.

\section{Introduction}

Mathematical Literacy has been instituted as a specific subject in South Africa for the last three years of schooling, the Further Education and Training (FET) phase (grades10, 11 and 12). All learners not selecting Mathematics will have to study Mathematical Literacy as a compulsory subject in the FET phase. This decision was reached after much discussion and debate on issues around the compulsory nature of forms of mathematical studies for all learners in the FET phase. Some of these issues were differentiation in mathematical studies, the mathematics needed for entry into tertiary studies and the possibility that learners in schools in particularly low socioeconomic environments will be doomed to mathematical studies of some inferior nature. Notwithstanding these debates and differences of opinion there is agreement that a mathematically literate populace is needed and schools should produce such graduates.

The debates and deliberations referred to above were conducted in various forums mostly by academics from tertiary institutions. In this paper some of the constructs emanating from these debates and deliberations and related constructs emanating from the literature specifically linked to what the goals of Mathematical Literacy should be are discussed in relation to the National Curriculum Statement (Grades 10-12 - General): Mathematical Literacy (Department of Education, 2006a). The constructs are: the teachability of Mathematical Literacy, the lack of a recreational component in Mathematical Literacy, Mathematical Literacy and an action component, the dilemma of contexts for Mathematical Literacy and the resilience of people's qualitative improvised strategies to resolve quantitative dilemmas.

\section{A note on Mathematical Literacy}

Mathematical Literacy is variously defined. These definitions can be deemed as on a continuum. At the one end of the continuum, Mathematical Literacy is viewed as entry into Mathematics and at the other end as a means to interact with mathematical installations in society. Exemplary of "Mathematical Literacy is viewed as entry into Mathematics" definition is that given by Kilpatrick (2001). He introduces the term "mathematical proficiency, defining it in terms of five interwoven strands to be developed in concert." And according to him "mathematical literacy...fits very well [with] mathematical proficiency" (Kilpatrick, 2001: 106-107, italics in original). The five strands are: conceptual understanding, procedural fluency, strategic competence, adaptive reasoning and productive reasoning. In his explanations of these strands, Mathematical Literacy as entry into Mathematics comes through clearly. For example, adaptive reasoning is the "capacity for logical thought and for reflection on, explanation of, and justification of mathematical arguments" and productive disposition "includes the student's habitual inclination to see mathematics as a sensible, useful, and worthwhile subject to be learned, coupled with a belief in the value of diligent work and in one's own efficacy as a doer of mathematics" (Kilpatrick, 2001: 107).

The other end of the definition continuum is driven by Skovsmose's critical mathematics education paradigm (Skovsmose, 1994). He coined the term mathemacy and explains it in an enquiring way as follows: 
As the notion of critical education developed, literacy was seen as a competency which enabled students to see and reinterpret part of (their) reality and to react to this reality...The essential question for critical mathematics education, then, is whether or not it is possible to develop a competency, mathemacy, which has a potential similar to that of literacy and which may help students to reinterpret their reality and to pursue a different reality? (Skovsmose (in collaboration with Nielsen and Powell), 1995: 7-8).

Critical Mathematical Literacy has a focus on citizenship and an interest in mathematical models structuring social life. There is a specific interest in the critique of such models (see for example Julie, 1998a and Gellert, 2004). Skovsmose (2004) provides a kind of technique to identify the "mathematics in action" regulating societal matters. Julie (2006) argues that in essence this "mathematics in action" is actually "mathematics in and for action". In this paper the definition of Mathematical Literacy as in the region of the Critical Mathematical Literacy guided the interrogation of the South African National Curriculum Statement (NCS) (Grades 10-12 General): Mathematical Literacy (Department of Education, 2006a) and some issues surrounding the implementation of this subject.

Of the principles underpinning the NCS (Grades 10-12 - General): Mathematical Literacy, "social transformation" and "human rights, inclusivity, environmental and social justice" (Department of Education, 2006a: 1) indicate some support for Critical Mathematical Literacy. This is further buttressed by the definition of Mathematical Literacy given as:

Mathematical Literacy is a subject driven by life-related applications of mathematics. It enables learners to develop the ability and confidence to think numerically and spatially in order to interpret and critically analyse everyday situations and to solve problems. (Department of Education, 2006a: 9)

However, as will be discussed below, there is still some way to go for the realisation of a Critical Mathematical Literacy education at least at the level of the intended curriculum. Notwithstanding this intention, any curriculum has to be taught in schools and hence this issue is discussed in relation to the teaching of Mathematical Literacy in the next section.
The teachability of Mathematical Literacy It is a widely held opinion that Mathematical Literacy is more difficult to teach than the "normal" school-going mathematics. At a meeting, organised by Higher Education South Africa (HESA), to discuss the Mathematics and Mathematical Literacy in the Revised Curriculum Statement for the Further Education and Training band this issue was raised. One of the participants related how this difficulty manifested itself when a highly adept and well-versed teacher experienced this difficulty when teaching Mathematical Literacy to a group of preservice teachers. The teacher also referred to similar experiences when discussing Mathematical Literacy at a regional meeting of the Association for Mathematics Education of South Africa. Although no firm evidence about the difficulty of teaching of Mathematical Literacy was offered at the two meetings, the general noddings and "oohs" and "aahs" of the audience gave the impression of a general agreement that Mathematical Literacy is indeed difficult to teach. Is Mathematical Literacy really that difficult to teach? Is it teachable at all? In order to understand this it is necessary to delve into notions of teaching and the development of teachable products.

Teaching is a deliberative act in which a knowledgeable person relays her/his understanding of a body of declared and established knowledge to someone not as yet knowledgeable about this body of declared and established knowledge. ${ }^{1}$ This relaying includes revealing and providing opportunities for engagement with the domain's navigational technologies and the necessary skills for the construction of artifacts deemed belonging to the domain. It is a social activity having a distinctly historically-developed-and-changing identity in distinct settings. Teaching a group of grade 1 learners, although there are overlaps, has a different identity from that of teaching a group of grade 9 learners. Within this process of relaying, values are implicitly relayed and appropriated. There are, amongst others, the values of mathematics per se i.e. of "the nature of mathematics", the values the teacher holds with respect to the goals of teaching and the values the learners bring to and appropriate in the classroom. The implicit relaying of values is in many

\footnotetext{
1 The presentation of teaching as "relay" does not exclude teaching underpinned and informed by one or other form of constructivism as a theory of learning. In fact, most constructivist-inspired teaching has elements of the expository teaching and vice versa. Exposition is more implicit in constructivist-inspired teaching and the other way round in expository. The difference thus is one of degree and not of kind.
} 
instances in the form of "anecdotal mentioning" in statements such as "Mathematics has always played a role in war and the money spent on it can be better used for feeding the poor of the world" when teaching quadratic theory and doing an applications-like problem on the distance traveled by a projectile. Or through "admonishing statements" such as "Can you see that if we just follow the applications of the definitions and the theorems we logically come to the desired conclusion. In a lot of issues in real life, it is also like this - do the things logically from the start and a defensible conclusion will follow" after, say, demonstrating the method for dealing with a geometry rider. Both these utterances are not what are being explicitly taught. They emerge if and when the teacher finds it opportune to make these utterances and so brings to bear his/her value positions on the situation at hand - expenditure on warfare versus expenditure on feeding the poor and destitute or the power of the mathematical-like rule-following in a closed system as a desirable form of logical reasoning.

Teaching is decidedly different from what happens when a member of a knowledge-making community informs and conveys her/his frontier knowledge products to the affiliated knowledgemaking community. In this instance he/she is not relaying declared and established knowledge. Rather, she/he is bringing to the affiliated community her/his knowledge constructs at the frontiers of a field in a discipline. This knowledge is not-yet declared, established and vetted by the community. Frontier knowledge is not relayed but rather co-explored by a community of practitioners in order to make it part of the body of declared and established knowledge of the domain.

It is not a given that after declaration and establishment a body of knowledge is immediately teachable. To become teachable, especially as school knowledge, it has to and does go through a series of transpositions from its declarative and established forms (Artique, 1994: 28). These are didactical transpositions and it is through mathematical didactical analysis that the subject matter is made amenable for school teaching. Mathematical Literacy, in its variety of presented definitions, as a domain of declared and established knowledge needs to proceed through a similar set of didactical analyses to make it teachable. If now the claim is made that it is more difficult to teach Mathematical Literacy than other school-going mathematics then it seems wise to search for this "difficulty" at the level of the processes of didactical analysis of Mathematical
Literacy from its definitions to school-teachable knowledge. The difficulty, I contend, has to do with some inadequacies of the didactical analysis process. These inadequacies can have various sources. Two of the most important sources are:

(1) Lack of epistemic dependence on experts Wittmann (1998) defines the core task of Mathematics Education, as a field of study, as the development of learning resources which lead to productive and meaningful learning. He argues that mathematics educators play a crucial role in this regard and that one of their tasks is the didactical analysis of subject matter to design school learning resources. This process, Wittman insists, is not the primary task of teachers because they do not have the time to do this. This "not having the time" to engage in the act of didactical analysis is also the case with "subject advisors" within departments of education. Wittman's proposal is essentially a call for the epistemic dependence on experts which Hardwig (1985) presents as having “...good reasons for believing a proposition if one has good reasons to believe that others have good reasons [and] that...because the layperson is the epistemic inferior of the expert (in matters which the expert is expert), rationality sometimes consists in refusing to think for oneself." Didactical analysis by mathematics educators as experts should render an elementarised and integrity-preserving version of the body of knowledge which is in principle teachable for the level for which this body of knowledge is elementarised. The experts elementarise this body of knowledge through theorisation and thought-experimentation which leads to hypothetical learning trajectories. This does not guarantee that the hypothesised trajectory will work in the real classroom situation. This leads to the second inadequacy in the process followed with respect to Mathematical Literacy.

\section{(2) Lack of experimentation with hypothetical teaching trajectories}

There is emerging realisation that teaching products should be designed and developed along the same lines as engineering products are developed (Burkhardt and Schoenfeld, 2003). Such a process, it is argued, will increase the likelihood that the distance between the intended and implemented is decreased. Teachable products should thus be obtained through a process of research and development with real classrooms as phenomenal domains and sites of experimental implementation. This process has not, as yet, been followed for Mathematical Literacy in South 
Africa. It appears that the expectation is that teacher inservice providers will develop learning resources for courses that will be offered to teachers. These materials should then form the basis for classroom learning resources. The problem with such an approach is that it does not provide an empirical base of learner handling of subject matter. There is emerging acceptance that learner handling of subject matter should form an integral part of the desirable knowledge that teachers should be exposed to. The integration of learner handling of school-going mathematics and the school-going mathematical content is increasingly gaining acceptance as a particular kind of mathematics - mathematical knowledge for teaching (Ball and Bass, 2000). Design research conducted with real classrooms as phenomenal domains will provide such knowledge of learner behaviour and such knowledge is virtually nonexistent for school-going Mathematical Literacy. It should not now be concluded that a research and development approach will render teacher-proof teaching products. Teachers always amend and adapt products to fit the contextual demands they are faced with. However, having exemplary teaching products informed by the reality of classrooms will provide teachers with a more considered base from which to make their decisions, amendments and adaptations.

The seeming difficulty of teaching Mathematical Literacy is thus more a system-level problem than a teaching problem. Despite the issue of the teachability of Mathematical Literacy, there are others that need highlighting in order for the NCS (Grades 10-12 -General): Mathematical Literacy to move towards the expressed intentions.

\section{Lack of a recreational component in Mathematical Literacy}

The second chapter of the NCS (Grades 10-12 General): Mathematical Literacy (Department of Education, 2006a) is a discussion on the purpose, scope, educational and career links and the learning outcomes. Conspicuous in this discussion is the absence of reference to mathematics as recreation. Recreational mathematics is a fairly well-established activity. It is commonplace to find books and articles of a mathematical recreational nature. The many books by, for example, Gardner (1981) and others attest to this. If one takes the view of a well-rounded and educated person also being someone who participates in some form of recreational activity then recreation through mathematics cannot per se be excluded from the arsenal of recreational pursuits such a person can engage in.

One definition of Mathematical Literacy is provided by the Program for International Student Assessment (PISA) (OECD, 2000). This definition is in terms of the desirable outcomes and is stated as "to make well-founded judgments and to use and engage with mathematics in ways that meet the needs of that individual's life as a constructive, concerned and reflective citizen" (OECD, 2000: 21). This definition privileges citizenship and awareness-building of a participatory democracy. Even if it can be argued that remotely "needs" is inclusive and that anything can fill this "needs" slot, it is unlikely that "needs" would be beyond what will appear in Mathematical Literacy examinations. Thus "recreational" mathematics will be suppressed or even disallowed and excluded.

\section{Lack of an action component}

In the discussion on the purpose of Mathematical Literacy attention is given to citizenship. It is stated:

To be a participating citizen in a developing democracy, it is essential that the adolescent and adult have acquired a critical stance with regard to mathematical arguments presented in the media and other platforms. The concerned citizen needs to be aware that statistics can often be used to support opposing arguments, for example, for or against the use of an ecologically sensitive stretch of land for mining purposes. In the information age, the power of numbers and mathematical ways of thinking often shape policy. Unless citizens appreciate this, they will not be in a position to use their vote appropriately. (Department of Education, 2006a: 10)

This points in the direction of the exclusion of an action component. Mathematical Literacy is embedded in the applications of mathematics and mathematical modelling. Mathematical modelling and the applications of mathematics are essentially about the development of some mathematical technology to realise a certain objective. This objective is an action objective. For example, if a mathematical model is developed to predict the supply and demand of teachers then the action objective is to plan in such a way for the education of teachers so that the demand will be met. Although it can be argued that the NCS (Grades 
10-12 - General): Mathematical Literacy does include an action component, it is rather a removed futuristic one. So, for instance, dealing with investments and their growth has limited, if any, immediate action value for the majority of learners who will be following the Mathematical Literacy curriculum. There are, however, instances of engagement with issues in Mathematical Literacy where learners should be sensitised to the possibilities of action due to the outcome of the analysis of the situation by mathematical means. In his inaugural address as professor of Applied Mathematics at the University of Cape Town, Ellis (1976: 17) highlights this notion of action and asserts that if the results from a mathematical analysis illuminate profound injustice of a politically-instituted practice then non-action is meaningless. After analysing the growth of pass law arrests and finding its exponential growth pattern, he asserts

...the only true basis of freedom is a realistic vision of the alternative possibilities before us. Mathematical studies can sometimes help us in understanding what alternative possibilities are. But such an understanding is quite valueless unless it affects our actions. An understanding of the courses of any social wrong, which does not lead to some corrective action to right that wrong, is meaningless. (Ellis, 1976: 17)

Thus through Mathematical Literacy it is not only an analytical competence that needs to be developed but also an action competence. This competence is viewed as making decisions individually or collectively and embarking on action, based on the decisions, to address the issue at hand (Jensen and Schnack, 1997: 168-169).

\section{The dilemma of contexts in Mathematical Literacy}

The NCS (Grades 10-12 - General): Mathematical Literacy, as is the case for other definitions of Mathematical Literacy, gives much attention to the desirable contexts to be used. Which contexts to use in Mathematical Literacy is a complex issue. In her statement that "organizing a lawn mowing business in math class is neither real lawn practice nor real school practice" (Lave, 1988: 20), Lave brings forth the dilemma of context and this is repeated by Muller when he states that contextually-driven mathematics "is neither 'real' mathematics nor recognizably 'real life'." (2000: 67). Muller (2000), drawing heavily on Dowling's
(1998) work, essentially argues against the use of contexts emanating from the life-world of learners from marginalised and poverty-infested backgrounds since according to him this will not provide such learners with the necessary "article of universally recognized cultural capital such as a school diploma [which] confers symbolic power on the holder" (Muller, 2000: 62). The mathematical knowledge, preferred by Muller, that should be distributed for the attainment of such a "school diploma" is that which is an elementarised version of Pure Mathematics. A careful study of the NCS (Grades 10-12 - General): Mathematical Literacy (Teacher Guide) (Department of Education, 2006b) indicates that this is subtly the case for Mathematical Literacy at the suggested implemented curriculum level.

It is not only the 'unreality' of contexts that is an issue. Pollak (1969) drew attention to context problem types and identified "five problem types that are normally included under the rubric 'application of mathematics'." He further "discards three of these [contexts problem types] as inappropriate since they do not take into account the complexity of the world outside of mathematics or their reality is fairly unreal" (in Julie, 1998b: 294). According to Julie (1998) Pollak suggest two desired problem contexts. The first is closed context problems - problems for which the model of a contextual situation is essentially provided and the learners explore the given mathematical model. The other is the open type context problem - "Problems which emulate the... way applied mathematicians would receive a problem, in all its complexity, from a commissioning agency" (Julie, 1998b: 294). Busse and Kaiser (2003) draw attention to the changes a context undergoes when encountered by a learner. They distinguish between objective figurative context - "the real description of the real scenario" and the subjective figurative context - "the interpretation of the objective figurative contexts" (Busse and Kaiser, 2003: 4). Their proposition is that it should not be unquestionably accepted that there is a one-to-one mapping between the contexts as presented in a task and contexts as interpreted by learners. The issue of learning transfer and the use of context is discussed by Boaler (1993) and she suggests "that contexts may be useful in relation transfer even though contexts as generally used are not useful" (Boaler, 1993: 13, italics in original).

Skovsmose (1998) addresses the question of using contexts emanating from the immediate environment of the learner. He argues that in their 
daily trade practices people do not view the work they are doing as essentially mathematical. They are simply exercising their skills and competences dealing with the job at hand. Thus, Skovsmose argues, a tailor is doing tailoring and not the mathematics of mapping a two-dimensional cloth in the plane to a three-dimensional body in space. True there is nothing wrong with this argument but it cannot serve as reason for prohibiting someone else from addressing such an issue from a mathematical angle. In fact, there are many instances, as Skovsmose admits in his tailoring example, where the mathematical description of some human activity served as inspiration for the development of some form of mathematics. In addition to the argument about the nonmathematical attention people involved in activities and practices, other than visibly mathematical work, give to their work, Skovsmose also advances the argument that learners are generally not interested in dealing with activities from their backgrounds. He proposes that contexts dealing with possible futures of learners should be foregrounded as an alternative. Using piloting as an example to be foregrounded, Skovsmose realises the problematic he is confronted with. It is this: His father was a tailor and he would have been averse to deal with the mathematics of tailoring in his school mathematics classes. But he was (and presumably still is) not interested in piloting.

The crux of the question of desirable contexts to be used in Mathematical Literacy is a major dilemma facing mass schooling and education, and can be captured as "What are the contexts and situations within which school-learning activities should be embedded so that they will appeal to all learners to be constructively engaged in the learning to be fostered by these contextuallyembedded activities?" The NCS (Grades 10-12 General): Mathematical Literacy (Teacher Guide) (Department of Education, 2006b) indicates that not much attention has been given to this issue. In most instances contexts emanated from curriculum and learning resource designers' perceptions on what preferred contexts should be.

\section{The resilience of the mixture of qualitative and quantitative procedures to resolve everyday quantitative dilemmas}

A feature standing out in Mathematical Literacy for school-going is that school-goers should develop competence to use mathematics in their daily lives. The manifestation of this desire is that issues and situations such as shopping, baking, cooking and everyday financial calculations are used as contexts for mathematical treatment. Whilst not arguing against this there is not clarity for which issues in their daily lives ordinary people actually need mathematical calculations and procedures. I argue that those situations in which people use mathematical ways in some instinctive way should not be colonised for classroom use and teaching, no matter how much mathematical elegance might be extracted from such activities. Meeting a self-employed, self-appointed and nonunionised porter at the airport I got involved in a discussion with her about her work and the amount of money she earns. The conversation went as follows (in the primary language of the porter and myself, of course).

CJ: Hoeveel maak jy nou op 'n dag?

P: As't goed gaan da ga ek hystoe met about 'n honerd, one fifty 'n dag. Dit depend oek of ek dollars of ponne kry, nie rante nie. Die Americans en die anne mense gie altyd dollars ma die Engelse mense gie ponne, daai dik coins.

CJ: Hoe exchange jy dit na rante?

P: Ek ga sommer hie na ABSA da binne en dan change hulle't vi my.

CJ: Hoe wiet djy dat hulle gie vir jou die regte amount?

P: Hulle sal my nie rob nie. Hulle ken al vi my. Maar ek kyk oek na rie bod. Nou is 'n dollar ampe tien rand. As ek drie dollars het dan moet hulle vi my ampe dêtig rant gie. Die bank moet mos altyd iets kry vi hulle expenses. Soe hou ek trek.

CJ: Jou kinners oppie skool. Wat sal djy laaik hulle moet leer van dié goed?

P: Niee, hulle moet lee wat die teachers ŝe hulle moet lee.

In summary she told me that she earned about one hundred to one hundred and fifty rand per day. She gets her "tips" from tourists in dollars or pounds and reads on the display board at the bank at the airport what the exchange rates are. She then does an approximation and works in some additive and qualitative way by anchoring on some whole number. This is not a strange way of working. People, regardless of levels of education, do such qualitative calculations all the time and my contention is that no amount of schooling will change this.

As already stated, to change ordinary commonsense ways to mathematical ways and hope that people will apply such in their day-to-day mathematical-like activity is folly. People do not 
walk around with abstract mathematical models in their heads. When confronted with a mathematicallike dilemma they resort to qualitative ways of dealing with these dilemmas and utilise all sorts of contextually-driven procedures to resolve these dilemmas. The social history of Mathematics indicates clearly that Mathematics has both a qualitative and quantitative dimension with the quantitative one having been accorded the status of Pure Mathematics. Kaplan (1999) in his social history of zero masterfully illustrates the acceptance of zero qualitatively before its acceptance as a quantity. This gives credence to the rallying assertion of Realistic Mathematics Education (Gravemeijer, 1994) that "reality is the source and domain of application of mathematics". This might now mean that the common-sense qualitative ways that people use to resolve their day-to-day quantitative-like dilemmas should be incorporated in Mathematical Literacy. This will require that learners be exposed to many such common-sense qualitative ways of resolving dayto-day quantitative dilemmas so that generalisable patterns across contexts can be observed. This moves us into the domain of contexts as vehicles for the development of mathematical concepts, procedures, relationships between concepts and justifications for such relationships. This is antithetical to the objective of Mathematical Literacy defined in the negative as not working at the frontiers of mathematical knowledge production but using existing mathematical knowledge to read, analyse, build alternatives and act in the world.

\section{Conclusion}

Mathematical Literacy is here to stay. Globilisation, the availability of technology allowing for the access to knowledge in an unprecedented way and the world-wide thrust for regular testing of the state of Mathematical Literacy in a country through international comparative studies such as TIMMS contribute favourably to the maintenance of Mathematical Literacy. However, as pointed out above, Mathematical Literacy is fraught with myths, omissions and unwarranted ambitions. Mathematical Literacy should, I contend, contribute towards the development of a "scientific temper" (Russell, 2001) which he argues is important for the maintenance of a culture of nondomination and non-discrimination. A Mathematical Literacy not contributing to this will be futile and be nothing more than a $21^{\text {st }}$ century version of arithmetic which, in South Africa at least, was devised to maintain discrimination and domination.

\section{References}

Artique, Michèle. (1994). Didactical Engineering as a framework for the conception of teaching products. In R. Biehler, R. Scholz, R. Strässer, and B. Winkelmann Bernard (Eds.), Didactics of Mathematics as a Scientific Discipline (pp. 27-39). Dordrecht: Kluwer Academic Press.

Ball, Deborah L., and Bass, Hyman. (2000). Interweaving content and pedagogy in teaching and learning to teach: Knowing and using mathematics. In J. Boaler (Ed.), Multiple perspective on mathematics teaching and learning (pp. 83-104). Westport, Connecticut: Ablex Publishing.

Boaler, Jo. (1993). The role of mathematics in the classroom: Do they make mathematics more 'real'? For the Learning of Mathematics, 13(2), 12-17.

Burkhardt, Hugh, and Schoenfeld, Alan H. (2003). Improving Educational Research: Toward a More Useful, More Influential, and BetterFunded Enterprise. Educational Researcher, 32(9), 3-14.

Busse, Andreas, and Kaiser, Gabriele. (2003). Contexts in application and modeling - an empirical approach. In Y. Qi-Xiao, W. Blum, S. K. Houston, J. Qi-Yuan (Eds.), Mathematical modelling in education and culture: ICTMA 10. (pp. 3-15). Chichester: Horwood Publishing.

Department of Education. (2006a). National Curriculum Statement Grades 10 to 12: Mathematical Literacy. Pretoria: Department of Education.

Department of Education. (2006b). National Curriculum Statement Grades 10 to 12: Mathematical Literacy (Teacher Guide). Pretoria: Department of Education.

Dowling, Paul. (1998). The Sociology of Mathematics Education. London: The Falmer Press.

Ellis, George. (1976). On Understanding the World and the Universe, Inaugral lecture, Cape Town: University of Cape Town.

Gellert, Uwe. (2004). Didactic material confronted with the concept of mathematical literacy. Educational Studies in Mathematics, 55, 163179.

Gardner, Martin. (1981). Mathematical Circus. Harmondsworth, Middlesex: Penguin Books.

Gravemeijer, Koeno. (1994). Educational Development and Developmental Research in 
Mathematics Education. Journal for Research in Mathematics Education, 25(5), 443-471.

Hardwig, John. (1985). Epistemic Dependence. Journal of Philosophy, LXXXII (7), 335-349.

Jensen, Bjarne Bruun, and Schnack, Karsten. (1997). The Action Competence Approach in Environmental Education. Environmental Education Research, 3(2), 163-178.

Julie, Cyril. (1998a). The production of artifacts as goal for school mathematics. In A. Olivier and K. Newstead (Eds.), Proceedings of the $22^{\text {nd }}$ international conference for the psychology of mathematics education, Volume 1. (pp. 49-65). Stellenbosch: University of Stellenbosch.

Julie, Cyril. (1998b). Prospective South African teachers' handling of pedagogical activities related to the applications of mathematics. In P. Galbraith, W. Blum, G. Booker, and I.D. Huntley (Eds.), Mathematical modeling: Teaching and assessing in a technology-rich world (pp. 291-300). Chichester: Horwood Publishing.

Julie, Cyril. (2006). Teachers' preferred contexts for mathematical literacy and mathematics for action. In Proceedings of the 14th Annual SAARMSTE Conference (pp. 46-55). Pretoria: University of Pretoria.

Kaplan, Robert. (1999). The Nothing That Is: A Natural History of Zero. London: Penguin Books.

Kilpatrick, Jeremy. (2001). Understanding mathematical literacy: The contribution of research. Educational Studies in Mathematics, 47, 101-116.

Lave, Jean. (1988). Word problems: A microcosm of theories of learning, Unpublished mimeo. Berkeley: Graduate School of Education, University of California.
Muller, Johan. (2000). Reclaiming Knowledge: Social Theory, Curriculum and Education Policy. London: Routledge/Falmer.

Organisation for Economic Co-operation and Development. (2000). Measuring Student Knowledge and Skills. Paris: OECD

Pollack, Henry. (1969). How can we teach the applications of mathematics? Educational Studies in Mathematics, 2, 393-403.

Russell, Bertrand. (2001). The scientific outlook. London: Routledge

Skovsmose, Ole. (1994). Toward a Critical Philosophy of Mathematics Education. Dordrecht: Kluwer Academic Publishers.

Skovsmose, Ole (in collaboration with Lene Nielsen and Arthur Powell). (1995). Critical Mathematics Education. Research Report R-952023, Aalborg University: Department of Mathematics and Computer Science.

Skovsmose, Ole. (1998). Critical Mathematics Education. In C. Alsina, J.M. Alvarez, M. Niss, A. Perez, L. Rico, and A. Sfard (Eds.), Proccedings of the $8^{\text {th }}$ International Congress on Mathematics Education (pp. 413-425). Seville: S.A.E.M Thales.

Skovsmose, Ole. (2004). Mathematics in action: a challenge for social theorising. Philosophy of Mathematics Education Journal. Retrieved May, 15, 2005 from http://www.ex.ac.uk/ $\sim$ PErnest/pome18/contents.htm

Wittman, Erich, C.H. (1998). Mathematics Education as a 'Design Science'. In A. Sierspinska and J. Kilpatrick (Eds.), Mathematics Education as a Research Domain: A Search for Identity. Dordrecht: Kluwer Academic Publishers.

A habit of basing convictions upon evidence, and of giving to them only that degree or certainty which the evidence warrants, would, if it became general, cure most of the ills from which the world suffers. 